\title{
Injections: Need for Reduction, Safety and Appropriateness
}

\author{
Atul Kotwal \\ Department of Community Medicine (PSM), Armed Forces Medical College, Pune 411 040, India.dratulkotwal@gmail.com
}

$\mathrm{A}$ t present, doctors and needles seem to go together. The needle signifies the power to heal through hurting and condenses active practitioner and passive patient. Like the hollow fangs of the snake, which curls around the staff of Aesculapius, the needle penetrates and perpetuates our power(1). However, in recent years there has been an increasing concern over the widespread misuse of injections(2). The alarming extent to which unnecessary and unsafe injections are administered has been studied extensively. Mathematical models have been created suggesting a large proportion of $\mathrm{HBV}, \mathrm{HCV}$ and $\mathrm{HIV}$ infections might result annually from unsafe injections(3).

The transition to safe injection practices i.e. reduced frequency, increased safety and appropriate sharps waste management needs to be undertaken immediately, to reduce further transmission of blood borne infections and avoid cases of abscesses, paralysis and other complications(2). A broad, multi disciplinary approach addressing policies, standards, systems, behavior and technology may ensure injection safety(4).

The number of injections can be reduced by efforts to wean populations away from injection overuse and encourage towards oral medications. This involves behavioral change of clients and prescribers/injection-givers through a combination of a supportive environment and information, education and communication (IEC) activities. Efforts are currently on worldwide to coordinate activity, advocacy for changes in policy, define standards for safe injections, develop new behavior, take advantage of health care reforms, increase the availability of safer injection technologies, promote appropriate waste disposal and define adapted IEC strategies(4).

Studies have shown that health workers seem to be convinced about the superiority of injections and therefore administer far too many injections than are medically justified; additionally, injections were given to meet the desired needs of the patients(5). This need might be either perceived by the provider or made explicit by the client by a nonverbal cue like positioning of their body, rolling up of sleeve etc. Few patients were even found to be giving a verbal request. This situation could be the result of misunderstanding between health staff and patients when the former simply assumed that the latter desired an injection and the latter are accepting the injections because refusal would indicate non compliance or lack of faith(6). This cognitive dissonance has been clearly demonstrated in a study in Indonesia. The knowledge, attitude, practices and perceptions of prescribers/providers need to be influenced by training and communication to enable them in choosing treatment wisely on evidence, increased awareness regarding unsafe injection practices, and their risks, and consequences and provide all medication by safest and most appropriate route. Workshops, interactional group discussions and health education campaigns have been shown to be effective(7).

In this issue of Indian Pediatrics, a well designed randomized controlled trial showing the effectiveness of interactional group discussion approach in reducing the frequency of injections has been published(8). The limitations in the conduct of the study have been aptly mentioned by the authors. The 
foremost being contamination as the control arm too showed reduction in the number of injections, the other limitations being issues of sustainability and Hawthorne Effect. Similar studies in different settings and with designs incorporating follow up need to be carried out to strengthen the evidence for interactional group discussions in reducing the number of injections. Even then, there is enough evidence from various settings, for Interactional Group Discussions to be included as one of the components of the overall strategy to reduce injections.

In addition, we must not forget the need to make the injections being given as 'safe'. The cultural meaning of injections, their place in medical practice, their influence upon human relations, financial gains/expenses involved and many other issues make the injections a very complex issue which has to be tackled by a multi dimensional and multi disciplinary approach. Locally relevant research into various aspects of injection practices should provide quantitative and qualitative information on injection practices. Ultimately, global demand for injections is fuelled by the perceived therapeutic effects. The risks are also linked to issues of lack of equity in health care. Thus, to succeed, strategies to reduce injections and to make them safe have to address the disparities and divides in accessibility and affordability of health care and international pressures of drugs and technology; otherwise unnecessary, unsafe and improperly disposed injections will continue to spread infectious diseases and possibly create new ones, throughout the 21 st century.

Funding: None.

Competing Interests: None stated.

\section{REFERENCES}

1. Brokensha G. The hollow needle: inappropriate injection in practice. Australian Prescriber 1999; 22: $145-147$.

2. Kotwal A. Innovation, diffusion and safety of medical technology: injection practices through a review of literature. Social Sci Med 2005; 60: 1133-1147.

3. Hauri AM, Armstrong GL, Hutin YJF. Int J STD AIDS 2004; 15: 7-16.

4. Hutin YJF, Chen RT. Injection safety: a global challenge. Bull WHO 1999; 77: 787-788.

5. Kotwal A, Priya R, Thakur R, Gupta V, Kotwal J, Seth T. Injection practices in a metropolis of North India: perceptions, determinants and issues of safety. Indian J Med Sci 2004; 58: 334-344.

6. Reeler AV. Anthropological perspectives on injections: a review. Bull WHO 2000; 78: 135-143.

7. Hadiyono JEP, Suryawati S, Danu SS, Sunartono, Santoso B. Interactional Group Discussion: Results of a controlled trial using a behavioral intervention to reduce the use of injections in public health facilities. Social Sci Med 1996; 42: 1177-1183.

8. Bhunia R, Hutin YJF, Ramkrishnan R, Ghosh PK, Dey S, Murhekar M. Reducing use of injections through "Interactional Group Discussions": A randomized controlled trial. Indian Pediatr 2009: 46; 409-414. 